Esperança Cardeira ${ }^{1}$

Universidade de Lisboa

Faculdade de Letras

Centro de Linguística
UDK: 323.1(=134.3) ; 81.323.1

https://doi.org/10.18485/imp.2017.ch.2

\title{
IDENTIDADE E NORMA NA HISTÓRIA DO PORTUGUÊS
}

\begin{abstract}
A variação e a mudança são caraterísticas comuns a todas as línguas vivas. O ser humano tem a capacidade de manter consistentemente a sua língua, sempre a mesma e sempre diversa, ajustando-a de modo a que esteja em consonância com as mudanças do mundo. As normas linguísticas não poderiam deixar de seguir a evolução natural e irrecusável da sociedade: tal como para as normas sociais, também para as normas linguísticas se pode traçar um percurso que acompanha a história da comunidade. A elaboração da norma linguística é inerente à do idioma nacional: ambas são produtos de planificação e visam criar uma identidade comum, fundada na história e na língua. O conceito 'língua portuguesa' resulta de um processo de construção dessa identidade, cujas raízes se encontram num período anterior à fundação de Portugal e que se estabiliza a partir do século XV, através da literatura e da reflexão metalinguística. Mas, como o português é uma língua viva, a(s) norma(s) estão em constante mudança.
\end{abstract}

Palavras-chave: norma linguística, idioma nacional, história do português, português médio, gramáticas, prosa historiográfica, elaboração da língua.

\section{A construção da identidade}

Por volta de 1175, no final do reinado do primeiro rei de Portugal, principia o período da história da língua portuguesa conhecido como 'arcaico' ou 'galego-português', iniciado com as suas primeiras manifestações escritas. Esta língua, em que foram elaboradas tantas composições poéticas, é a continuação de um romance oral nascido no noroeste peninsular, sobre base latina, e com uma personalidade forjada pelos substratos pré-latinos e pelos superstratos de origem germânica e árabe, bem 
como pelas circunstâncias históricas do povoamento e pelas caraterísticas da geografia física e humana. Mas para que este romance se transformasse em 'língua portuguesa' foi necessário que se delimitassem fronteiras políticas, que se criasse um centro de poder e que se edificasse uma identidade nacional.

\subsection{Língua e história}

O romance oral da Galécia Magna acompanhou a Reconquista cristã, pelo menos nos primeiros tempos. A Reconquista fez-se por etapas, com avanços e recuos, ao longo do espaço e do tempo: a região do rio Douro foi conquistada por volta do ano mil, Coimbra em 1064; em 1135 a construção do castelo de Leiria assegurou a colonização a sul de Coimbra, e em 1147 a defesa da linha do Tejo permitiu a colonização da Estremadura e do Ribatejo. No final do século XII Sancho I conquistou parte do Alentejo e do Algarve mas foi forçado a recuar e Afonso III só conseguiria recuperar esses territórios em meados do século XIII.

Quer isto dizer que no século XII, quando surgiram os primeiros documentos escritos, o reino de Portugal se centrava na área setentrional, grosso-modo até Coimbra. Por essa altura florescia uma poética a que os filólogos vieram a chamar 'galego-portuguesa'. Quem a cultivava, no entanto, provavelmente não sentiria que escrevia em 'galego-português' mas em 'linguagem', por oposição a 'latim'. A expressão galego-português aparecerá mais tarde, com o estudo filológico da poesia medieval de poetas galegos, portugueses e de outras proveniências, que elaboravam cantigas numa modalidade literária do romance desenvolvido no noroeste. Mas as populações da Galiza e de Portugal não aplicavam de forma estável, pelo menos até ao século XIV, um nome à língua que falavam. Um nome cria uma realidade, e uma língua independente precisa de nome próprio. Ora, sem fronteiras políticas bem definidas e, principalmente, sem consciência de 'nacionalidade' é duvidoso que os falantes reconhecessem uma identidade própria ao contínuo linguístico que ocupava todo o noroeste da Península Ibérica. Quanto à documentação não literária, se usarmos o rio Minho como fronteira, talvez possamos dizer que o que se escrevia acima do Minho era galego, e o que se escrevia 
abaixo do Minho era português. São, contudo, mais uma vez, designações extemporâneas, que decorrem da perspetiva de quem, agora, olha para trás; é pouco provável que acima ou abaixo do rio Minho as pessoas se sentissem 'diferentes'. É certo que Clarinda Maia (1986) regista algumas escolhas divergentes nos documentos produzidos na Galiza e no noroeste português, logo nos séculos XIII-XIV. Ainda assim, ao lermos aqueles textos, dificilmente poderemos afirmar que essas divergências ultrapassam a normal variação dialetal.

A Reconquista e, principalmente, o Repovoamento trazem este romance oral para sul: primeiro entre o Mondego e o Tejo, criando uma zona de transição que partilha dialetalismos setentrionais e meridionais (atual grupo dos dialetos do centro litoral, estremenho e beirões). ${ }^{2}$ A conquista desta região terminou no século xII e a eficácia da colonização garantiu uma difusão continuada do romance do noroeste, ao fixar populações setentrionais nos territórios a sul, à medida que iam sendo conquistados.

Situação diferente é a que encontramos do vale do Tejo até ao Guadiana (atual grupo dos dialetos do centro interior e sul, ribatejano, baixobeirão, alentejano e algarvio): aí a conquista concluiu-se mais tarde, na primeira metade do século XIII, e o repovoamento não teve a mesma intensidade. O menor afluxo de colonos vindos do Norte e a distribuição inicial de vastas propriedades pelas ordens militares não alterou significativamente a fraca densidade populacional. Nesta região, o romance nascido no noroeste, e transplantado da sua área original, vai difundirse num ambiente de contacto de línguas e dialetos; colonos portugueses e de diferentes proveniências regionais (galegos, leoneses, castelhanos, francos, flamengos...) e diferentes modos de falar vêm somar-se às populações autóctones árabes, hebraicas e moçárabes. Com o tempo, o contacto entre estas variedades vai favorecer o nivelamento linguístico, através do uso preferencial das caraterísticas comuns a todos os dialetos e do abandono das que os diferenciam. Daqui resulta uma variedade simplificada e regularizada do romance arcaico, uma coiné que, inicialmente, terá funcionado como língua franca da nova comunidade de fala, mas que se desenvolveu rapidamente como língua materna. 
Será sobre este romance do sul que se irá construir um modelo de língua portuguesa, no que constitui já uma segunda fase evolutiva do 'português arcaico', que poderemos designar por 'português médio'. O que determina a seleção do romance meridional como modelo linguístico são fatores de natureza histórica e política: desde inícios do século XII era em Coimbra que se localizava o centro político e cultural do reino e, a partir do século XIII, esse centro desloca-se gradualmente para sul, primeiro para Santarém e depois para Lisboa. Após a revolução de 1383-85, a área de influência política e cultural do Reino fixa-se definitivamente no espaço centro-meridional, com sede em Lisboa. Pela mesma época, a queda da nobreza setentrional tem como consequência o desprestígio das suas caraterísticas linguísticas e o português culto distancia-se, então, das origens e inicia um processo de elaboração. É durante a primeira metade do século XV que se desenvolve este processo, através da eliminação de dialetos em torno de um centro hegemónico, a corte de Avis. Funcionando como força aglutinadora, a nova corte vai unificar o idioma, absorvendo as distintas áreas dialetais e marginalizando as caraterísticas do Norte, que passam a ser encaradas como regionais, ao mesmo tempo que a língua incorpora muitas das inovações da mistura de subsistemas linguísticos que constituía a coiné medieval, resultante do repovoamento da área centro-meridional.

É claramente anacrónico falar em 'idioma nacional' no século XV, mas é nessa altura que começa a ser atribuído à língua um potencial político, enquanto símbolo de um império e do poder monárquico. Não é ainda língua nacional porque não é a língua do povo mas apenas a do rei; mas é a língua do rei que vai modelar a língua do povo, funcionando como base da futura estandardização da língua, materializada na fixação iniciada na primeira metade de quinhentos com a publicação das gramáticas de Fernão de Oliveira e de João de Barros.

Se a primeira fase do português arcaico escrito (até finais do século XIV) continua uma antiga unidade linguística, um romance com origem na Galécia Magna, que, no continuo dialetal da România, se foi lentamente distanciando dos seus congéneres, a segunda fase, a que já podemos, com segurança, chamar português, o português médio do século XV, afasta-se dessa primitiva unidade por um processo de elaboração. Olhando para as 
mudanças linguísticas, verificamos que os documentos escritos em português apresentam, ao longo do século XV, um conjunto de alterações que transfiguraram radicalmente a língua, que se libertou da Idade Média e dos seus traços arcaizantes e passou a configurar um patamar mais estável e próximo do português moderno: resolveram-se os hiatos, unificaram-se as terminações nasais, regularizou-se a flexão verbal e nominal, apurou-se a construção frásica e ampliou-se o léxico. Estas mudanças concentram-se na primeira metade do século XV: o final do século XIV carateriza-se por uma variação estável - há variação mas não há, ainda, seleção de variantes; a seleção e, portanto, a mudança, tornam-se efetivas em meados de quatrocentos; segue-se um período de estabilização das variantes selecionadas, entre finais do século XV e meados do XVI. ${ }^{3}$

Este conjunto de mudanças, que ocorre no espaço de cerca de 50 anos, afasta o português, quer do antigo romance ocidental, quer do galego. Uma vez que estas mudanças resultam de variantes selecionadas pela língua da corte, e que as variantes abandonadas são as setentrionais, o afastamento aparece como voluntário. Voluntário, porque a variação linguística só se transforma em mudança quando uma variante é aceite pela comunidade, eliminando as outras. Ora, isso só acontece quando uma determinada camada social escolhe uma variante e a difunde por toda a comunidade, criando uma norma. Essa camada social, detentora do prestígio que permite ditar normas, seria, no século XV, a Casa de Avis.

\subsection{Gramáticos e cronistas}

Tal como seria um anacronismo falar de 'idioma nacional' quando nos referimos ao século $\mathrm{XV}$, também não poderemos falar de 'identidade nacional'. Penso, no entanto, que é precisamente nesse século que se lançam as fundações destes conceitos. O 'idioma nacional' começa a constituir-se por um processo de elaboração linguística e literária, que passa quer pela estandardização, quer pela afirmação da diferença em relação a outras línguas. Paralelamente, começa a surgir uma incipiente noção de 'identidade', composta por um conjunto de traços que modela uma comu-

3 Dito de outro modo: a análise da variação do português médio mostra que a mudança linguística é um processo não-linear, com períodos em que a língua 'salta' de um patamar para outro ( $v d$. Cardeira 2005). 
nidade: as fronteiras políticas, as crenças comuns, a língua, a história e, principalmente, a afirmação da diferença em relação a outras culturas.

Já a primeira dinastia portuguesa, a dinastia de Borgonha, tinha sentido necessidade de afirmar a sua autonomia em relação aos reinos vizinhos e, para isso, precisava de contar com o apoio da Igreja. Portanto, o caminho a seguir seria apresentar Afonso Henriques como instrumento de Deus e o reino de Portugal como baluarte da Igreja. É o que encontramos nos Milagres de S. Vicente. ${ }^{4}$ Mas o poder de Afonso Henriques era, ainda, um poder de um senhor entre senhores. A dinastia de Avis, por outro lado, precisava não só de assegurar a autonomia do reino mas também de afirmar o poder do rei e da casa real. Não pretendo, de modo nenhum, reclamar para Portugal a iniciativa de centralizar o poder e criar uma nação em torno da corte régia. Pelo contrário: a crise da emergência das nacionalidades estava, naquele princípio do século Xv, a alastrar pelas cortes da Europa ocidental. O que quero sublinhar é que Portugal não estava isolado no seu cantinho do oeste peninsular e que participou ativamente neste processo. Do mesmo modo, a 'questão da língua', que acompanhava a emergência das nacionalidades, também se refletiu nas primeiras gramáticas portuguesas. Simplesmente, aqui não se tratava apenas de valorizar a língua 'vulgar' face ao latim mas, também - e, talvez, principalmente - de a afirmar, pela diferença, frente ao vizinho castelhano. Por isso, Fernão de Oliveira (1536) defende que o rei de Portugal não seja "el rei" mas "o rei", e que a sua gente tenha "linguagem não mal misturada mas bem apartada".

Este objetivo de apartar a língua, de a individualizar, encontra paralelo no louvor da gente que a fala, expresso frequentemente em fórmulas como "a língua de tão nobre gente e terra como é Portugal", "principal entre muitas", "nós portugueses", "nós, que não somos latinos", "esta nossa terra Portugal", "a nossa língua" e, até, "quem folga d'ouvir língua estrangeira na sua terra não é amigo da sua gente". É essa língua bem apartada, bem distinta, que se constitui como património ou, nas palavras de Fernão de Oliveira "fiel tesoureira do bem de nossa sucessão".

A conceção da língua como património casa perfeitamente com a estratégia de concentração do poder em torno do rei. Trata-se de criar 
símbolos para um império em construção: o rei, a língua, a história. A dinastia de Avis percebeu a necessidade de unir um reino fragmentário, criando elementos comuns que viriam a permitir o nascimento de uma memória coletiva e de uma consciência nacional. Por isso, as primeiras gramáticas do português (Fernão de Oliveira, 1536, e João de Barros, 1540) seguirão na esteira do desenvolvimento da prosa histórica, que surgira por impulso da nova dinastia.

A partir de 1434, as crónicas fornecem uma versão oficial da história, instrumento político manejado pelos reis, que têm consciência da sua importância enquanto elemento identitário e fator de coesão. As crónicas põem em relevo os feitos memoráveis e apenas os feitos memoráveis e pintam um quadro povoado de santos e heróis mesmo que para isso seja necessário, por vezes, manipular um pouco a realidade. É o que faz Zurara, ao criar a lenda henriquina. E é o que faz Rui de Pina, quando, ao relatar a morte 'santa' de D. João I, a adianta de um dia, para que o dia da morte coincida com os dias do nascimento, da conquista de Ceuta e da batalha de Aljubarrota. Assim se cria a imagem de um rei predestinado a ser um messias para Portugal (Sousa 2009).

Naturalmente, quer a construção da história quer a da língua estão, no caso português, estreitamente ligadas ao empreendimento expansionista, que exigia a funcionalização da língua vulgar e a criação do mito de um povo missionário. Os cronistas encarregam-se do mito, os gramáticos da língua; a visão do expansionismo linguístico como instrumento de missionação e de soberania fica bem clara nas palavras de João de Barros (1540): "Certo é que não há glória que se possa comparar a quando os meninos etíopes, persianos, índios, [...] em suas próprias terras, na força de seus templos e pagodes [...] aprenderem a nossa linguagem, com que possam ser doutrinados em os preceitos da nossa fé, que nela vão escritos". A nossa linguagem, tal como a nossa fé e a nossa história tornamse assim elementos aglutinadores e símbolos de um império centrado à beira do Tejo.

Na segunda metade do século XVI, as circunstâncias históricas juntaram o reino de Portugal a Espanha, durante 60 anos. Nesse momento, a situação do português poderia ter-se tornado semelhante à do galego, subalternizado a uma outra língua de cultura. Mas, por essa altura, as 
fronteiras do reino já eram estáveis e a língua já estava consolidada. Por isso, os escritores portugueses puderam conviver com a literatura castelhana sem abandonarem a língua portuguesa. Se, sob o domínio castelhano, os portugueses sentiram que tinham perdido a independência foi precisamente porque antes se sentiam independentes. Foram estes portugueses que levaram a sua língua nas caravelas, uma língua que se tornou língua franca do mar oceano e que continua, ainda hoje, a unir cinco continentes.

\section{A construção da norma}

Um fator determinante na construção de uma identidade 'portuguesa' foi a estandardização da língua. A partir de meados do século XV, a expansão ultramarina obrigou à reflexão metalinguística: o conhecimento de novas línguas, bem como a necessidade de criar instrumentos para o ensino do português, conduziram à elaboração de dicionários, cartinhas e gramáticas. Tudo isto num momento em que se desenvolve a imprensa, que permite propagar a língua vernácula por um número cada vez maior de falantes. E os dicionários, as cartinhas, as gramáticas implicam a constituição de uma norma para a língua.

Historicamente, não é difícil delinear os passos necessários para a criação da norma (em especial a norma escrita): as gramáticas estabelecem princípios reguladores para a fonologia, a morfologia e a sintaxe; os dicionários definem o léxico; a ortografia regulariza a escrita; a literatura fornece um modelo a seguir; o ensino divulga princípios e modelos. Difícil é definir o próprio conceito de 'norma'.

\subsection{Norma, gramáticos e linguistas}

Uma pergunta que é frequentemente colocada aos linguistas é "Onde se fala melhor, em Coimbra ou em Lisboa?" Esta pergunta tem variantes: "nesta frase, qual é a palavra ou a construção mais correcta?" Estas questões prendem-se com a definição do conceito de norma e não são boas perguntas para se fazer a um linguista. Não porque os linguistas desconheçam qual

é a forma mais correta de uma frase ou de uma palavra mas porque não é

60 
esse o seu principal interesse. São os gramáticos que fazem da 'correção linguística' o centro do seu trabalho. Gramático e linguista não são sinónimos, embora alguns linguistas também sejam gramáticos.

A Gramática é uma disciplina muito antiga, anterior a Jesus Cristo. Durante muitos séculos não existiram linguistas, apenas gramáticos. Os linguistas são uma classe muito mais recente, que só surge no século XIX. O objeto de estudo do gramático (refiro-me, claro, ao gramático tradicional; um gramático moderno é, também, um linguista) e do linguista é o mesmo - a língua - mas a perspetiva é diferente. Os gramáticos descrevem a língua não como ela é mas como eles acham que ela deve ser. A Gramática tem uma vocação normativa e pedagógica e encara a língua como um meio (de falar, escrever e pensar bem, de ter um bom lugar na sociedade, etc.). A Linguística, por outro lado, encara a língua como objeto de conhecimento. Os linguistas descrevem a língua como ela é e estudam-na para saberem como funciona.

Quando folheamos uma gramática tradicional ficamos com a impressão de que está lá tudo o que precisamos saber: bastará seguirmos à risca todas as regras e saberemos falar e escrever corretamente. Mas não é assim: a língua é mais complicada do que aquilo que está na gramática. O linguista pretende descrever essa complexidade e, como não tem, necessariamente, que fazer juízos de valor sobre a língua, encontrase numa posição privilegiada para a apreciar.

Nos finais do século xIX Adolfo Coelho (1870: 7-8) definia magistralmente estas duas perspetivas, afirmando-se claramente linguista e distanciando-se dos gramáticos, ao dizer:

Para mim a língua é um facto, cujos momentos e génese trato de estudar, sem atender ao resultado prático que possa provir do meu estudo. Escreve-se de certo modo, fala-se de certa maneira: a minha questão está em saber por que é que assim se escreve, por que é que assim se fala. É o ponto de vista científico. Não pretendo ensinar como se deve escrever português, podia até ser incapaz de escrever um só período nesta língua e conhecer-Ihe todavia perfeitamente as origens e transformações.

Dito de outro modo: a Gramática é prescritiva, a Linguística é descritiva. A gramática tradicional, normativa, decorre de um processo subje- 
tivo, um juízo de valor sobre a língua e o seu bom uso, que encontra os seus fundamentos numa visão historicista da língua. A Linguística atual, por outro lado, busca retratar a língua tal como ela é, elaborando gramáticas descritivas que resultam de processos objetivos de análise e que pretendem mostrar a variação e a dinâmica do sistema linguístico.

\subsection{A variação e a(s) norma(s) linguísticas}

Dizer que a Linguística se preocupa em descrever a língua tal como ela é pode dar a ideia de que os linguistas não se preocupam com o 'certo' e o 'errado'. Não é assim. Mas antes de definirmos 'certo' e 'errado' precisamos de distinguir o plano 'ideal' (em que se encontra a normapadrão) do plano da 'realidade'. Ora, a realidade é que qualquer língua viva é um multifacetado sistema em constante mudança. O sistema linguístico a que chamamos português, por exemplo, é um conjunto de variedades: não se fala nos Açores como em Lisboa, não falamos agora como falavam os nossos antepassados. Nem sequer falamos como escrevemos e falamos de formas diferentes consoante a pessoa a quem nos dirigimos. A língua portuguesa regista, como todos os sistemas linguísticos, variação geográfica, histórica, social e situacional. Cada uma destas variedades

é, em si mesma, um sistema dinâmico e complexo, com uma particular combinação de elementos e regras (portanto, com normas). É o conjunto de todos esses sistemas que constitui um sistema mais amplo, o português. Cada falante do português domina, pelo menos, o dialeto da região de que é originário e o dialeto do grupo profissional a que pertence. Por outro lado, um falante dos Açores não conhecerá as caraterísticas peculiares da variedade do Barlavento Algarvio, tal como um jovem que domina perfeitamente o léxico estudantil desconhecerá muitas palavras utilizadas pelos seus avós. Significa isto que todos os falantes conhecem uma parte da língua portuguesa mas nenhum a domina por completo: todos falamos português mas ninguém é 'dono da língua' porque ninguém a conhece completamente.

Um dos dialetos da nossa língua, que se espera que conheçamos, é a 'norma'. A norma linguística é uma espécie de 'super-dialeto' que todos sabemos existir sem o sabermos definir com exatidão. Normas são todas 
as regras que organizam a nossa vida. A língua, que faz parte da nossa vida, também se regula, naturalmente, por normas. E como a língua é um conjunto de variedades e cada uma dessas variedades se rege por normas, todos os dialetos, sejam eles regionais ou sociais, têm uma norma (entendida como um conjunto de regras). Isto quer dizer que não há 'certo' e 'errado' em abstrato mas apenas no concreto, na situação. Na verdade, todos nós sabemos que o 'certo' e o 'errado' dependem das circunstâncias. É por isso que sabemos adequar a nossa linguagem às circunstâncias e não falamos com um superior hierárquico da mesma maneira que conversamos com um amigo. Aprendemos isso como aprendemos todas as outras regras de comportamento em sociedade.

Ora, se todas as variedades que compõem a língua têm normas, a que é que chamamos 'norma linguística'? Pode dizer-se que há um conceito amplo e um conceito estreito de norma. No conceito amplo pensamos em norma como o modelo, o padrão da língua. Este padrão resulta de uma construção secular, baseada na literatura consagrada e funciona como um fator de identidade nacional e coesão social. A história do nosso país, a nossa língua, a nossa literatura, dão-nos uma identidade, fazemnos sentir portugueses.

Uma língua não é apenas um meio de comunicação mas é também uma instituição social, no sentido em que é uma construção histórica e um importante fator de unificação da comunidade. Na história de uma língua, há momentos em que, através de instrumentos como a gramática e a ortografia, a língua se torna instituição, escolhendo um dos seus dialetos como modelo. Essa escolha não é linguística mas social e política. Quando o ensino transmite um determinado modelo de língua está a perpetuar um determinado modelo social.

Em Portugal, como vimos, a partir do século xV, os dialetos entre Coimbra e Lisboa foram escolhidos como modelo porque aí estavam sediadas a corte e a aristocracia, que funcionavam como modelos para a sociedade.

No século XVIII, Luis António Verney escrevia, no Verdadeiro Método de Estudar (1746): "em matéria de pronúncia, sempre se devem preferir os que são mais cultos e falam bem na Estremadura, que todos os das outras províncias juntas". Pela mesma altura António José dos Reis Lobato (1771), confirmava esta preferência, no que diz respeito à escrita, dizendo 
"julguei que devia seguir a ortografia que vejo usada pela Corte". Estava, portanto, decidida a definição e a localização da norma: era a língua das pessoas cultas da corte. A definição resulta claramente de uma perspetiva sócio-política: a norma é a língua do poder e situa-se onde se situa o poder. Ao poder associa-se o saber: tradicionalmente, o saber linguístico é apanágio dos 'bons escritores'. Mas uma definição de norma como 'a língua dos bons escritores' não é, seguramente, uma boa definição. Quem são os bons escritores? Camões? Vieira? Mas quem não se riria de nós se escrevessemos hoje como eles escreveram há séculos? Esta definição de norma, no sentido de 'padrão linguístico', parece-nos, hoje, um conceito muito ligado à literatura e muito afastado da realidade. Há, no entanto, um conceito de norma que se cola mais à realidade. É o conceito estreito, a norma como sinónimo de 'português culto', de português falado por uma classe social a que atribuímos prestígio. Sob um ponto de vista estritamente linguístico, todas as variedades têm o mesmo valor. É no plano social e não no linguístico que uma variedade vale o que valem os seus falantes e tem o prestígio que eles têm.

\section{3. $A(s)$ norma(s) em mudança}

Enquanto instituição, a língua é património da comunidade, um bem de todos nós e para o qual todos contribuimos. Todos temos o direito de a mudar e o dever de a conservar. Mas conservar não significa congelar. Uma vez que a língua, enquanto instrumento de comunicação, serve a sociedade, se a sociedade muda a língua também tem de mudar. Se as normas que regem o nosso comportamento social mudam, também as normas linguísticas mudam. A mudança, em si, não é novidade. A mudança é, mesmo, uma constante de qualquer língua viva. A espécie humana muda regularmente o seu sistema de comunicação.

Se consultarmos um dicionário elaborado há pouco mais de um século, como o Novo Dicionário da Língua Portuguesa de Cândido de Figueiredo ${ }^{5}$, encontraremos na entrada pedófilo (ou pedophilo, porque também a grafia mudou) a seguinte definição: "aquele que gosta de crian-

5 A primeira edição deste dicionário é de 1899; até hoje foi objeto de 25 reedições; a 2a edição, de 1913, encontra-se disponível on-line. 
ças". A sociedade mudou e agora, no Dicionário Houaiss da Língua Portuguesa (2001), pedófilo é "o indivíduo que se sente sexualmente atraído por crianças". Se todos os dias surgem novas palavras, há outras que desaparecem ou mudam de sentido. É por isso que os dicionários deveriam ser revistos, atualizados e 'limpos' periodicamente.

Mas se a mudança é uma constante da língua, uma constante da sociedade é a reação contra a mudança. Julgo que a face mais visível desta reação à mudança, no que toca à língua, diz respeito à ortografia e aos empréstimos linguísticos. Mesmo antes da reforma ortográfica de 1911, Alexandre Fontes (1910) dizia: "Imaginem esta palavra phase escrita assim: fase; não nos parece uma palavra, parece-nos um esqueleto". Comparemos esta afirmação com a de Sophia de Mello Breyner, em 1986: "A escrita tem um carácter emblemático que é perigoso perturbar. Por exemplo: ação parece o nome de um pássaro!" (jornal Expresso, 21.6.1986).

Hoje os portugueses sentem a sua língua ameaçada pela globalização, que arrasta consigo a hegemonia do inglês. Tememos que a enorme quantidade de novas palavras de origem inglesa modifique a feição da nossa língua. Também isto não é novidade. Há cerca de uma centena de anos, Cândido de Figueiredo, em Os Estrangeirismos (1902), condenava o uso do anglicanismo entrevista e propunha entrefala para o substituir.

Mas nessa época era principalmente o francês que era visto como ameaça. Parecem-nos agora completamente portugueses os galicismos detalhe, conduta ou cave mas a verdade é que são importações que foram, na altura, repudiadas. Sobre o uso de detalhe e detalhar diz Cândido de Figueiredo: "se nós temos minúcias, pormenorizar, que cegueira é esta que nos leva a tolerar o exótico enxerto? Se o amor às nossas coisas ainda não se extinguiu de todo, dispam o detalhe, que é roupa alheia, e trajem a boa fazenda nacional." Quanto a cave e a conduta, diz o seguinte: "Cave não é português: é francês genuíno; e, se lhes não agrada ou acham longa a expressão adega ou frasqueira subtérrea, é tolerável dizermos cava"; "Conduta, conduzir-se, no sentido de procedimento, comportarse, são galicismos condenáveis, jamais perfilhados por escritor asseado".

Aos brasileiros também repugnavam os empréstimos: à entrada do século Xx, Castro Lopes, em obra com o sugestivo título Neologismos Indispensáveis e Barbarismos Dispensáveis (1909), propunha que se tra- 
duzisse turista por ludâmbulo, piquenique por convescote, menu por cardápio. Ludâmbulo e convescote não vingaram mas cardápio sim ${ }^{6}$.

Mais perto de nós, num livro de Martins Sequeira adequadamente chamado Rol de estrangeirismos e respectivas correspondências em português de lei (1950) figuram as seguintes propostas para travar a evolução: traduzir boxeur por murrista, camionete por autocarroça, croissant por meia-lua, cassetete por porrete, carpete por alfombra, derrapagem por escorregamento, embraiagem por engate, toilette por atavios, maionese por salgalhada, etc, etc, etc...

Voltando a Cândido de Figueiredo (1902), mais uma citação, agora gastronómica: "O puré entrou já em toda a parte. E contudo a forma portuguesa não é essa; é pureia. Eu bem sei que os usos são, às vezes, de uma força brutal; mas se os homens de boa vontade, reconhecendo a legitimidade da pureia, a fossem ensaiando contra o intruso puré, alguma coisa iria lucrando o bom senso e a língua".

Ora bem: como se vê, não dizemos entrefala, nem frasqueira subtérrea, nem ludâmbulo, nem convescote nem pureia. Parece que o bom senso não venceu e que os usos têm, de facto, uma força brutal.

\subsection{A variação, a(s) norma(s) e o ensino}

Não parece muito difícil, nesta época em que todos temos acesso ao ensino e à informação, sermos portugueses instruídos, que dominam a norma da sua língua. O problema é que vivemos um momento em que dispomos de imensa informação. Já não lemos só os bons escritores. Aliás, depois de irmos buscar a informação à televisão e à internet, não nos sobra muito tempo para lermos os bons escritores. Portanto, talvez a tal 'norma-padrão' ainda seja baseada nos bons escritores mas a norma real constrói-se agora a partir dos modelos que nos entram em casa todos os dias: os jornais, a televisão e a internet. Ora, estes modelos são muito mais imediatos e dinâmicos do que os modelos literários. Mudam muito e muito rapidamente. Neste momento parecem estar a mudar especial-

A fé de Castro Lopes na autoridade dos "Filólogos, Gramáticos, Mestres da linguagem" fica bem patente na sua afirmação de que "essas autoridades, pelas leis que decretam, devem ser respeitadas pela plebe insurgente e ignorante." 
mente depressa mas a verdade é que a sociedade também está a mudar a grande velocidade. Entraram em jogo muitos fatores de mudança, como a imigração e a internet, que não existiam no tempo dos nossos avós. $E$ os professores da língua portuguesa, que sempre se equilibraram sobre a frágil teia formada pela confluência da língua literária e da norma culta, da(s) norma(s) e das variedades de uso, do oral e do escrito, debatem-se, agora, com novos problemas.

O português está a mudar. A emergência da comunicação social (em que incluo a internet) tende a provocar um progressivo nivelamento linguístico que caminha no sentido da eliminação das variedades regionais. Uma política linguística para o português terá, futuramente, que se preocupar não somente com a defesa da língua mas também com a defesa das variedades dialetais, que constituem uma riqueza patrimonial que devemos preservar.

Tal como o ensino, também a norma se 'democratizou', tornandose mais acessível a todos, não só porque todos a podem aprender mas também porque se tornou mais real, mais próxima dos falantes que a ela acedem através do ensino e da comunicação social. Falo, naturalmente, do conceito estreito de norma, enquanto 'português culto' (melhor: português de um grupo de falantes escolarizados a que a sociedade atribui prestígio). Os nossos programas de ensino da língua refletem, cada vez mais, a preocupação em adequar a matéria de estudo a esse conceito estreito de norma, transmitindo conhecimentos fundamentais para a plena cidadania dos jovens: não basta saber ler e escrever, é preciso que o conhecimento da língua seja funcional, permitindo a compreensão e produção de textos a que somos quotidianamente expostos (textos jornalísticos, formulários, etc.). Isto não pode, no entanto, afastar do panorama os textos literários. A finalidade do ensino não é, apenas, transmitir a língua do quotidiano mas, também, o ideal linguístico que a norma literária representa e que a história construíu. Simplesmente, já não se pede ao professor que se limite a ensinar a língua 'tal como ela deve ser' mas também que a descreva 'tal como ela é'. E isso implica abordar a multiplicidade do sistema linguístico, falar em mudança, variação e norma(s), descrever e prescrever. O papel do professor torna-se cada vez mais difícil. 


\section{BIBLIOGRAFIA}

Barros, João de. Gramática da Língua Portuguesa, Lisboa: Luís Rodrigues, 1540. Impresso. [Web: http://purl.pt/12148/5/\#/12].

Cardeira, Esperança. Entre o Português Antigo e o Português Clássico. Lisboa: Imprensa Nacional-Casa da Moeda, 2005. Impresso.

Cintra, L. F. Lindley. Estudos de Dialectologia Portuguesa. Lisboa: Sá da Costa, 1983. Impresso.

Coelho, Francisco Adolfo. Algumas observações ácerca do Diccionario bibliographico portuguez e seu auctor. Lisboa: F. A. Coelho, 1870. Impresso.

Figueiredo, Cândido de. Os Estrangeirismos. Resenha e comentário de centenas de vocábulos e locuções estranhas à língua portuguesa. Vol.I. 6ạ Edição, corrigida e melhorada. Lisboa: Livraria Clássica Editora, 1956 [1902]. Impresso.

Figueiredo, Cândido de. Novo Dicionário da Língua Portuguesa, 1913 [1899]. Web: http://www.dicionario-aberto.net/.

Fontes, Alexandre. A Questão Orthographica. Lisboa: Tip. Anuário Comercial, 1910. Impresso.

Houaiss, Antônio e Villar, Mauro de Salles. Dicionário Houaiss da Língua Portuguesa. Rio de Janeiro: Objectiva, 2001. Impresso.

Lobato, António José dos Reis. Arte da Grammatica da Lingua Portugueza. Lisboa: Regia Officina Typografica, 1771. Impresso.

Lopes, Castro. Neologismos Indispensáveis e Barbarismos Dispensáveis. Rio de Janeiro: Francisco Alves, 1909. Impresso.

Maia, Clarinda de Azevedo. História do Galego-português. Estado linguístico da Galiza e do Noroeste de Portugal desde o século XIII ao século XVI. Coimbra: Instituto Nacional de Investigação Científica, 1986. Impresso.

Nascimento, Aires Augusto e Gomes, Saul António. "S. Vicente de Lisboa e seus milagres medievais". Didaskalia. Lisboa, 1985, 73-95. Impresso. [Web: http://hdl.handle.net/10400.14/15163].

Oliveira, Fernão de. Grammatica da Lingoagem Portuguesa. Lisboa: Germão Galharde, 1536 (ed. fac-similada Lisboa: Biblioteca Nacional, 1988). Impresso. [Web: http://purl.pt/120/3/\#/16].

Sequeira, F. J. Martins. Rol de estrangeirismos e respectivas correspondências em português de lei. Lisboa: Livraria Popular de Francisco Franco, s.d. [1950]. Impresso.

Sousa, Armindo. A morte de D. João I (um tema de propaganda dinástica). Lisboa: Fio da Palavra Ed., 2009. Impresso.

Verney, Luís António, Verdadeiro Metodo de Estudar: para ser util à Republica, e à Igreja. Valensa [Nápoles]: Antonio Balle [Genaro e Vicenzo Muzio], 1746. Impresso. [Web: http://purl.pt/118]. 


\title{
Esperança Cardeira
}

\section{IDENTITY AND STANDARD IN THE PORTUGUESE LANGUAGE}

\begin{abstract}
Summary
Variation and change are common features in all living languages. The human being has the ability consistently to maintain his language, always the same and always different, adjusting it in order to keep it in accordance with a changing world. Language rules, as social norms in the history of a community, could not fail to follow the natural and undeniable evolution of society. The development of a linguistic standard is inherent in the establishment of a national language: they are both products of planning and both aim to create a common identity, based on history and language. The notion of the "Portuguese language" follows the establishment of that identity, whose roots are to be found in a period prior to the foundation of Portugal. Since the fifteenth century literature and metalinguistic thought have attempted to standardize the national language but, because Portuguese is a living language, standard(s) are constantly changing.
\end{abstract}

Keywords: linguistic standard, national language, history of the Portuguese language, Middle Portuguese, grammars, historiography. 